\title{
Deus stultus: sobre el telos del sujeto contemporáneo
}

Alejandro Matos

Pontificia Universidad Católica del Perú

Resumen:

Tomando en cuenta la plasticidad del ser humano bajo la concepción kantiana (autonomía) o sartreana (autodeterminación) podemos afirmar que su autenticidad o esencia está en cierto grado mediada por la contingencia. Siendo este el caso, el presente artículo busca indagar, en las fuerzas de la tecnología y virtualidad presentes, algunas pistas para concebir un telos hipotético que nos dé una imagen de las próximas transformaciones que podría atravesar el sujeto contemporáneo. Aquí se presenta una antropología filosófica contextualizada por nuestra nueva cotidianidad maquínica y digitalizada.

Palabras clave:

Tecnología, Virtualidad, Antropología filosófica, teleología, Dios

\begin{abstract}
:
If we take into account the plasticity of human beings characterisctic of the kantian (autonomy) or sartrean (self-determination) conceptions, we can state that their essence or authenticity is, to a certain degree, mediated by contingency. With this being the case, the present article delves into the forces of current technology and virtuality aiming to find some clues to conceptualize a hypothetical telos capable of providing a picture of the following transformations that the contemporary subject could go through. Thus is a philosophical anthropology, framed by a new machinic and digitalized daily life, displayed here.
\end{abstract}

Keywords:

Technology, Virtuality, Philosophical anthropology, Teleology, God 


\section{§1. Humano y autonomía}

Empecemos por la pregunta inaugural de la antropología filosófica: ¿qué es el ser humano? Para ahorrarnos unos 2000 años de historia y darle curso a este limitado ensayo, vamos a darle la palabra directamente a Kant, para ser más específicos, al Kant del proyecto crítico. Bajo ese encuadre teórico, sería lícito pensar que el ser humano es como una $x$ a despejar, el resultado de una ecuación. La ecuación es la siguiente: si el motor del proyecto kantiano se nos presenta en la forma de las tres famosas preguntas ¿qué puedo conocer?, ¿qué debo hacer? y ¿qué me cabe esperar? Entonces la $x$ no será otra que ese sujeto tácito que se hace las preguntas: aquel que conoce, que debe y que espera. Así, el ser humano tendría la imagen de un sujeto en el cual confluyen una multiplicidad de facultades. De entre ellas, sería relevante destacar la autonomía, esa capacidad fantástica de darse uno su propia ley que solo se realiza fuera de la naturaleza, en una esfera llamada libertad. Es solo el ser humano y su bendita razón los que pueden autogobernarse y gobernar a la naturaleza desde un distintivo velo nouménico que los acoraza de la heteronomía.

Puesto así, podríamos concluir humildemente que, si el ser humano va a tener alguna suerte de esencia, esta estará asociada, más que a ciertos rasgos físicos, a una serie de propiedades intelectuales. Estemos muy de acuerdo o no con los pequeños detalles del arreglo metafísico de este Kant, aun así, podemos decir que por lo menos las facultades corporales han quedado libres de hacer crujir ese hielo delgado sobre el que se encuentra parada la humanidad. Son inocentes.

Absueltos ya de la paradoja de Teseo, habrá que dar otro convenido salto de dos siglos para seguir encaminados en esta ruta de la autonomía y la libertad. Toca darle voz a Sartre para enterarnos un poco sobre lo que podemos descubrir si radicalizamos aún más esta intuición kantiana sobre el ser humano. En síntesis, lo que va a anunciar el filósofo en todo el calor del siglo XX es la transición de la simple autonomía hacia la autodeterminación. El sujeto ya no es una confluencia de facultades dadas a priori como respuesta a las preguntas de un alemán muy astuto dentro de las cuales la autonomía es solo un ítem. Para Sartre, si algo vamos a predicar sobre el ser humano 
será no más que su libertad entendida como la obligación irrenunciable de autodeterminarse, autodefinirse. Irrenunciable precisamente porque este sujeto sobre el que preguntamos está forzado a vivir en un vertiginoso flujo temporal en el que, quiera o no, se está construyendo a cada instante mediante la acción. Para él, sencillamente somos una fáctica nada desposeída de todo a excepción de la potencia para procurarnos algo de esencia. Pero tampoco hay que perdernos completamente en el mar de los individuos, y Sartre estaba muy consciente de ello. ¿Qué hay de compartida en esa esencia que cada uno se da? Él decidió contestar del siguiente modo en una polémica conferencia: "Cuando decimos que el hombre se elige, entendemos que cada uno de nosotros se elige, pero también queremos decir con esto que, al elegirse, elige a todos los hombres" (Sartre 1945, 3). La condena al trabajo de la libertad tiene como producto algo compartido por todos: cada elección, cada acto, es un trazo en el proceso compartido de dibujar los contornos del ser humano.

He aquí nuestra nueva respuesta. La esencia del ser humano es un producto temporal de todos los esfuerzos de los sujetos al proyectarse en sus acciones. Podríamos quedarnos satisfechos con dicha respuesta abstracta, abierta e, irónicamente, indeterminada. Decimos que el ser humano es un proyecto animado y libre por obra de ni más ni menos que del absurdo. Ante una conclusión así habría que tener la decencia de por lo menos aclarar el estado actual de la cuestión, de esa esencia plástica que Sartre expone. ¿Quién puede hablarnos sobre la actividad más universal, determinante, abarcante y vital para el ser humano en la era contemporánea? Marx.

Esta actividad no es otra que el trabajo, y es por ello que llegamos a Marx mediante un silogismo simple: si la esencia humana viene determinada por los actos que proyectan a todo el colectivo de la especie y a la vez es verdad que el acto más aplastantemente basto en él es el trabajo, entonces Marx definitivamente tiene algo que aportar a esta indagación. Los Manuscritos económicos y filosóficos nos significan un buen contexto para inspeccionar algunos detalles de esta actividad. El texto sobre el trabajo enajenado nos muestra un choque importante con una idea que recuperamos de Kant: la esencia humana parece estar determinada por una actividad motivada por alguna facultad intelectual o distinta de la naturaleza. Existe una diferencia 
importante entre el trabajo animal y el trabajo humano. Mientras que el primero es una función mecánica del instinto guiada por la fisionomía natural que nos lleva a satisfacer nuestros apetitos y necesidades más básicas, el segundo es producto de una genuina volición depurada de las determinaciones animales, librada ya de la austeridad. En palabras kantianas, vemos aquí un trabajo regido por la heteronomía y otro por la autonomía. Esta puesta teórica se presta perfectamente para un relato sobre la historia humana que podríamos esbozar superficialmente de este modo: somos una multitud de sujetos que, luego de un largo proceso de reflexión, nos hemos hecho conscientes de nuestra facultad de autodeterminación. Pero, junto a este brillante descubrimiento se nos aparecen las cadenas de la animalidad esclava como gran antagonista para nuestra libre empresa de dibujar nuestra humanidad ideal. Le llamaremos historia al proceso de emancipación de la naturaleza inconsciente, cuyo fin se hallará en la erradicación del trabajo animal.

Por utópico o extraño que parezca este relato, no podemos decir que no haya influenciado en nuestro concepto implícito de progreso, el cual reconocemos de manera más palpable en los acelerados avances tecnológicos que venimos vivenciando desde hace varias décadas.

Imaginemos por un momento que, efectivamente, lográramos emanciparnos y acabar de una vez por todas con el trabajo animal y las condiciones precarias que lo posibilitan. En dado caso, ¿cómo se vería nuestra cotidianidad?, ¿cuál sería ese nuevo ser humano proyectado por nuestras acciones?, ¿cuál es el verdadero rostro de la libertad?

\section{§2. Teleología humana}

En filosofía no nos hace falta apoyo ni para imaginar, pues el primer interlocutor en esta tarea especulativa de adivinar la senda del ser humano libre lo hallamos desde la antigüedad: Aristóteles. La primera pista está en el libro primero de la Metafísica, en el cual hace una valoración holística y jerárquica de todas las ciencias según sus respectivos fines y alcances. En dicha escala, coloca a la técnica en tanto facilitadora de las necesidades 
más básicas del ser humano en la base. En el siguiente puesto coloca a las artes como proveedoras de placer. Y en la cúspide a las ciencias exactas y la filosofía primera en tanto fines en sí mismos, exentos de toda exigencia de utilidad, propias de los humanos más libres.

Si llevamos esta tesis hasta sus últimas consecuencias, podríamos imaginar un mundo hipotético en el cual ni los recursos básicos vitales ni el placer estético sean asunto de preocupación y todos los humanos se vuelvan paulatinamente en filósofos natos, siempre pensantes. Este calificativo de "siempre pensantes" tendría que llamarle la atención a cualquier lector de Aristóteles dada la descripción que él mismo hace de Dios en su obra. Uno de los rasgos que lo caracteriza y describe su actividad presente es precisamente el de ser pensamiento siempre en acto. Naturalmente, nosotros los humanos nos vemos atravesados por múltiples carencias e imperfecciones que nos alejan de este estado divino de pensamiento incesante. Claramente no somos monjes que hayan trascendido la subsistencia material, sino solo pensadores en potencia. Pero esta distancia entre nosotros y el dios aristotélico no debería hacernos perder de vista el hecho de que esta diferencia que hay en medio es de grado y no netamente cualitativa. La humanidad aquí se ve como una bisagra en la que se articula la animalidad y la divinidad. Dios sería hacia donde tendemos, el grado más elevado de libertad humana, el fin de la lucha contra las cadenas de la naturaleza.

Antes de proseguir en esa línea especulativa que sin problemas podría devenir en misticismo, habría que preguntarnos si es que efectivamente la humanidad está si quiera cerca o por lo menos encausada para alcanzar los ideales de esta narrativa de la emancipación. En tiempos de Keynes, cuando el capitalismo aún parecía ser compatible con este proyecto colectivo y universalista, se podría decir que sí se alcanzaba a ver un futuro en esa dirección. En una conferencia suya titulada Posibilidades Económicas para nuestros Nietos pronosticó que, si el crecimiento económico seguía las tendencias presentes, con una buena gestión sería posible que: “¡Y tres horas al día deberían ser suficientes para satisfacer al viejo Adán en la mayoría de nosotros!" (Keynes 1930). Ya en esa etapa de desarrollo se divisaba un futuro en el cual la jornada laboral iría disminuyendo precipitadamente hasta llegar a ser menos de la mitad. Él mismo en esa conferencia sostuvo la 
idea de que el gran problema de la economía de la gestión de los recursos escasos quedaría resuelto por fin y que la nueva ocupación de la humanidad sería mantener la paz y hallar nuevas formas más enriquecedoras de emplear su tiempo. Tomando en consideración todo el avance tecnológico realizado en estos últimos 90 años, tal vez, al menos desde el punto de vista de los medios materiales, no sea tan utópico echarle una mirada a este telos divino del ser humano libre.

Nuevamente, no habría que concluir de manera tan apresurada esta indagación sin haber explorado la otra cara de esos 90 años de avance tecnológico. Hoy por hoy, la clara línea que dividía a lo que en clave marxista sería el trabajo animal y el trabajo humano ha empezado a difuminarse. La distinción superficial que pone a las máquinas como facilitadoras de trabajos físicos y mecánicos y al ser humano en ocupaciones creativas y noéticas parece ya no hacerles justicia a las capacidades de la nueva tecnología. Los desarrollos en la inteligencia artificial y la algorítmica tendrían que motivarnos a pensar en cuáles son nuestras verdaderas facultades distintivas, ¿qué nuevas preguntas kantianas nos restará hacernos en el futuro?, ¿qué esencias podremos darnos en un mundo automatizado? y ¿qué lugar habrá de tomar el ser humano en un escenario de este estilo?

\section{§3. Tecnología noética}

Intentemos dar tiros al aire a ver si hallamos nuestra esencia en alguna actividad noética en particular: ¿calcular? no, ¿invertir? no, ¿planear? no, ¿memorizar? no, ¿buscar? no, ¿jugar? no, ¿leer? tampoco. De momento, estas actividades íntimamente vinculadas al pensamiento y nuestra capacidad intelectual han sido ya colonizadas por el campo de acción de la tecnología. De nuevo: ya no es lícito asociar únicamente las tareas físicas a las máquinas y las noéticas a las personas. Al menos en cuanto a lo que el pensamiento más cotidiano respecta, la tecnología ya es capaz en buena medida de hacerse cargo.

Si esta es la verdadera tendencia, la verdadera imagen del telos del sujeto contemporáneo, entonces parece ser que no hay un límite tan bien 
definido para las actividades que la tecnología puede llegar a realizar (y, en consecuencia, para lo que ya no nos sería necesario hacer). Para ahondar un poco en este punto podemos consultar el texto Automatic Society de Bernard Stiegler. La noción a rescatar aquí es el de la proletarización de las facultades noéticas. De manera análoga a cómo en el capitalismo hubo una proletarización de un sector mayoritario de la sociedad en la cual se disocian y descolocan los medios de producción respecto de los trabajadores con efectos alienantes, la inteligencia artificial y algorítmica se apropian o enjaulan nuestras facultades noéticas fuera de las fronteras de nuestra integridad psicofísica.

Ejemplos primitivos que presagian el futuro de este proceso de proletarización se encuentra en los algoritmos de predicción de frases en los motores de búsqueda (automatización de la sintaxis o formulación de ideas), los feeds de las redes sociales que jerarquizan en orden lineal la disposición de los contenidos (priorización impuesta de los tópicos de información), filtros y herramientas predeterminadas para la edición de imágenes (innovación artificial en la estética), anuncios comerciales determinados por actividad en múltiples aplicaciones (refinamiento del comprador consumista), etc.

Todas estas intervenciones en el uso de la inteligencia humana se sitúan en un territorio especial: la virtualidad. No es difícil pensar este espacio intangible como algo más que un llano refuerzo o expansión de nuestros medios de vida ordinarios. Un vistazo sensato a cómo operan estas redes de información nos sugiere entenderlo más como un laboratorio, donde los oferentes de estas plataformas y servicios digitales encuentran en el deseo tácito de eyectar nuestras facultades fuera de la primera persona un escenario ideal para conformar lentamente una nueva subjetividad más dependiente que nunca. Ya no hace falta llenar formularios o encuestas atravesadas por la críptica ambigüedad del lenguaje y la individualidad de cada consumidor para que los desarrolladores jueguen al psicoanalista y adivinen cuál será el siguiente experimento: hoy en día, basta con un par de cookies. Con esa opción disponible, la barrera del lenguaje queda anulada y prestamos acceso directo ya no solo al dominio de la palabra, sino además al del acto. Así, la virtualidad se vuelve un espacio de plena transparencia a sus ojos, donde todo tránsito deja huella y la privacidad de la mentira 
queda cancelada. No solo habría que considerar el asunto de si es posible que un nuevo sujeto efectivamente surja o no, sino también la cuestión epistemológica sobre si los fabricantes de esta nueva cotidianidad saben qué se avecina. Aquí vemos cómo la intensificación de la brecha entre los arquitectos de la virtualidad y los meros usuarios, con la alienación que ello conlleva, evoluciona en una división interna del sujeto vuelto dependiente, entre su cuerpo biológico y su fuerza de trabajo físico y noético.

Tal parece que el desarrollo de la técnica impulsado por el ser humano para librarse de las cadenas de la naturaleza no puede a su vez salvarlo de sí mismo. El telos del sujeto contemporáneo es transformarse en una criatura plenamente alienada y fragmentada. Las piernas para correr son reemplazadas por caminadoras y medios de transporte híper eficientes, las manos son reemplazadas por productos procesados, sistemas de aseo mecanizados e infraestructura automatizada, el rostro es reemplazado por avatares diseñados artificialmente, los ojos son reemplazados por pantallas y reproductores de video.

¿Cuál es aquella tarea verdaderamente esencial por la cual aceleramos todo el resto de tareas vitales? ¿Si cuerpo y mente son objetivados, materializados en artefactos ajenos, cómo podrá la nada sartreana darse algún contenido? Este mundo posible y los sujetos que lo habitan tienen un sabor agridulce. Se cumplen los requisitos fundamentales para llamarle Dios a ese ser humano creador de su propia libertad, pero tras haber empeñado todas sus fuerzas en alcanzarla, este termina inevitablemente vacío. Se deshace de todas las tareas, incluso de sí mismo. No puedo ver en una genialidad que persigue desenfrenadamente su inacción otra cosa que un proceso de idiotización. Si vamos a ser plenamente honestos con esta ruta argumentativa, habrá que admitir sus conclusiones en toda su amplitud, aunque ello nos lleve a un oxímoron: Deus stultus. En cierto sentido, la humanidad persigue su propia extinción para alcanzar una idiotez divina, para conciliar la comodidad de la muerte y la inacción con la estadía en el plano consciente de la vida. 


\section{Bibliografía}

Alba, Santiago y Carlos Fernández, 2010. El naufragio del hombre. Hondarrabia: Hiru Aristóteles, 1994. Metafísica. Madrid: Gredos

Deleuze, Gilles, 1999. Conversaciones. Valencia: Pre-Textos

Kant, Immanuel, 2013. Crítica de la razón práctica. Madrid: Alianza

Keynes, John, 1930. Posibilidades económicas para nuestros nietos. GESD. https:// arquitecturacontable.wordpress.com/2016/10/23/posibilidades-economicas-de-nuestros-nietos-j-m-keynes-1930/. Consultado 4 octubre 2021

Mandel, Ernest, 1979. El capitalismo tardío. Ciudad de México: Era

Marx, Karl, 2001. Manuscritos económicos y filosóficos de 1844. Marxists Internet Archive. https://www.marxists.org/espanol/m-e/1840s/manuscritos/index.htm Consultado 1 julio 2021

McLuhan, Marshall, 1996. Comprender los medios de comunicación. Buenos Aires: Paidós

Sartre, Jean-Paul, 1945. El existencialismo es un humanismo. Universidad Complutense de Madrid. https://www.ucm.es/data/cont/docs/241-2015-06-16-Sartre\%20 \%20El_existencialismo_es_un_humanismo.pdf Consultado 25 julio 2021

Stiegler, Bernard, 2016. Automatic society. Journal of visual art practice. http:// dx.doi.org/10.1080/14702029.2016.1228883 Consultado 25 julio 2021 